\title{
A Workflow for the Performance Based Design of Naturally Ventilated Tall Buildings Using a Genetic Algorithm (GA)
}

\author{
Humera Mughal ${ }^{1}$, Jose Beirao ${ }^{2}$ \\ ${ }^{I}$ Faculdade de Arquitetura da Universidade de Lisboa, Portogal; University of \\ Palermo, Italy ${ }^{2}$ Faculdade de Arquitetura da Universidade de Lisboa \\ ${ }^{1}$ humera.mughal@unipa.it ${ }^{2} j n b @ f a . u l i s b o a . p t$ \\ Optimization of Natural Ventilation process in highrise buildings is one of the \\ most complex and least addressed phenomenon in the field of sustainable \\ architecture. This issue requires urgent consideration to reduce the computation \\ time due to fast growing demand of vertical construction in metropolitan cities. \\ Until recently most highrise buildings have been operated with mechanical \\ systems, causing high energy loads in hot climates and have high carbon \\ footprints. Highrise buildings with natural ventilation and sky gardens can \\ address these problems. This study involves the development of a Genetic \\ Algorithm (GA) addressing the multi objective optimization of natural ventilation \\ in tall buildings incorporated with Sky-Gardens at different levels all connected \\ through a central ventilation shaft. The fitness function for this GA is composed \\ of three scales; temperature reduction due to evapotranspiration of plants of \\ sky-gardens, optimum wind velocity for channelizing air inside the corridors and \\ ventilation shaft, and optimum building configuration. The aim is to find the best \\ solutions for tall buildings constructed in hot climate through the provision of \\ optimized airflow paths suitable for the effectiveness of natural ventilation, within \\ a reasonably short computation time for supporting design processes at early \\ stage.
}

Keywords: Optimization, Natural Ventilation, Tall buildings, Genetic Algorithms

\section{INTRODUCTION}

High rate of urbanization in metropolitan cities and scarcity of land are instigating a high demand for vertical construction. High-rise/tall buildings, on the other hand, are consumers of natural resources and energy, adding new problems to the urban environment such as urban heat island effects and high carbon footprint. As, the global market is increasingly demanding more complex, functional and tall structures for office activities and accommodation requirements (Safarik, Ursini, \& Wood, 2018), the necessity to construct more environmental friendly buildings also increases. Environmental performance optimization of tall buildings using sustainable technologies if tested at an early design stage can significantly cut down carbon footprint and energy consumption (Trabucco \& Wood, 2016). However, environmental optimization studies especially for complex tall struc- 
tures are extremely time consuming and can delay the time needed to properly evaluate design alternatives.

Furthermore, unlike other fields of science, optimization in architecture is a complex and ambiguous process, because objectives are interdependent and optimizing one aspect can bring down the performance of other aspects. For instance, use of natural ventilation helps in reducing the cooling load for buildings in hot climate, however the quality of air it introduced in buildings may be polluted for example due to proximity to a heavy traffic urban area or industrial area causing health issues (Sev \& Aslan, 2014). Therefore, some problems are better understood when addressed and optimized locally, but others can only be addressed simultaneously. The whole process is cumbersome and sometimes exasperating for the designers. Furthermore, tall buildings are usually incorporated with hybrid ventilation systems failing to reduce the installation cost as well as energy consumption costs resulting from mechanical ventilation systems (Etheridge, 2008; Konis, Gamas, \& Kensek, 2016).

Use of Genetic Algorithms (GA's) in architecture is argued to be not just a trend but also a necessity (Fasoulaki, 2007), by playing a vital role in addressing the problem of multi-criteria optimization. When properly applied, it can be an efficient technique to optimize complex multi-variable problems and guide architects towards more efficient designs. Furthermore, the whole process and simulations can be run on standard PCs (Emanuele, Alessandro, Ivan, \& Yi, 2013). (Fasoulaki, 2007) integrating a generative model with a Genetic/Evolutionary algorithm used as an optimization tool for the calculation of design performance according to a fitness function.

Most of the previous studies focus on external building shape optimization to enhance building aerodynamic for effective urban wind flow using a generative model and GA, as done by (Bing \& Ali, 2015; Feng, Shuyi, \& Tong, 2016). However, this research focusses on optimization of air flow paths in terms of Area, position and shape of ventilation shafts and segmentation together with the overall building form/shape to find out the best solution with optimum wind velocity, air temperature and building configuration using generative model and GA.

\section{METHODOLOGY, RESEARCH PROCESS \& RESULTS}

The methodology involves two main phases (a) development of a generative model and (b) development of the optimization model using an Evolutionary algorithm. The Optimization model includes the definition of fitness function that in turns is dependent upon CFD simulation and building configuration. These two phases are explained in the following subsections.

\section{Development of the Generative Model}

The development of the generative model starts with the definition of the geometrical features that are needed to generate various, in fact as much as possible, tall building morphotypes, including the main architectural elements needed to promote natural ventilation, which can be summarized to be

- An inner ventilation shaft or chimney (Moghaddam, Amindeldar, \& Besharatizadeh, 2011; Mughal \& Corrao, n.d.; Oldfield, Trabucco, \& Wood, 2009); to help buoyancy effect in tall buildings that can also aid the effectiveness of cross-ventilation when the spaces are facing a tall open space such as an atrium. (Wood \& Salib, 2012).

- Segmentation with a set of green terraces called sky gardens (Etheridge, 2008; Wood \& Salib, 2013; Yang, Tu, \& Francis, 2004); that not only enhance natural ventilation but also provide better thermal conditions as compared to green balconies (Taib, Abdullah, Fairuz Syed Fadzil, \& Swee Yeok, 2010) by cooling down the local temperature to a maximum of $3^{\circ} \mathrm{C}$ (Raji, Tenpierik, \& van den Dobbelsteen, 2015). They also reduce congestion and provide better psychological im- 
Table 1

Variables and their ranges for developing parametric 3-D models of tall buildings

\begin{tabular}{llll}
\hline No. & Code & Variables & Range \\
\hline $\mathbf{1}$ & $\mathbf{A}$ & $\begin{array}{l}\text { Profiles Type or Building type }- \text { four different building profiles } \\
\text { responding to the same set of variables producing four types of base shapes } \\
\text { for floor plan }\end{array}$ & $1-4$ \\
\hline $\mathbf{2}$ & $\mathbf{B}$ & Fillet Radius on floor shape corners (m) & $0.0-2.0$ \\
\hline $\mathbf{3}$ & $\mathbf{C}$ & $\begin{array}{l}\text { Number of Floor Parts (number of sides of basic shape - applies to types } \\
\text { 3 and 4) }\end{array}$ & $2-8$ \\
\hline $\mathbf{4}$ & $\mathbf{D}$ & Floor surface width/ Side B (m) & $10-21 \mathrm{~m}$ \\
\hline $\mathbf{5}$ & $\mathbf{E}$ & Side X of Chimney (width of central air shaft) (m) & $10-50 m$ \\
\hline $\mathbf{6}$ & $\mathbf{F}$ & Side Y of Chimney (Length of central air shaft)-for floor type 4 only (m) & $10-50 \mathrm{~m}$ \\
\hline $\mathbf{7}$ & $\mathbf{G}$ & Scale Factor (distorts the plan according to an axis) & $0.2-1.2$ \\
\hline $\mathbf{8}$ & $\mathbf{H}$ & \# of floors per Section (between sky gardens) & $3-10$ \\
\hline $\mathbf{9}$ & $\mathbf{I}$ & \# floors per sky gardens or sky garden height & $1-4$ \\
\hline $\mathbf{1 0}$ & $\mathbf{J}$ & Rotation -Tower rotation angle (rotates floors) & $1.0-10.0$ \\
\hline $\mathbf{1 1}$ & $\mathbf{K}$ & $\begin{array}{l}\text { Step \# Floor per Section -Vertical shift per section given in number of } \\
\text { floors (slides sections vertically) }\end{array}$ & $0-3$ \\
\hline
\end{tabular}

pact in tall buildings (Oberndorfer et al., 2007) together with increasing the wind velocity and consequently the natural ventilation phenomenon by improving the permeability of building (Mohammadi, Calautit, Mohammadi, \& Calautit, 2019; Mughal \& Corrao, n.d.; Niu \& Burnett, 2001; Yang et al., 2004).

These parametric models follow some scientific rules, stated below:

- External aerodynamic forms (Circular or oblique outer form of building) lessen the wind loads on the structure, and the rotating external shapes develop the effective pressure differences for efficient natural airflow. Furthermore, the shape of floor plan defined in a way that it helps entering the outdoor wind from multiple facades of building (i.e. polygon, oval), improves the natural ventilation (Bing \& Ali, 2015).

- A min of 10 meter and max of 21 meter of floor width/plan depth from central core can be ventilated through natural wind flow processes as for effective cross-ventilation, the depth of the room must not exceed five times its height i.e. $3.5 * 5=17.5$ meter (Kubota \& Ahmad, 2006) So this is a parametric variation of what can be considered a normal building depth, both in terms of cross-ventilation and access to natural light

- The shape of central core/chimney can vary for the effective natural ventilation process with the Width of chimney no less than 10 meters.

- Researchers agree that a tall building can be represented through the use of 60 floors or (Serras \& Valente, n.d.; Skyscrapercentre.com/ctbuh.org, 2019; Wood \& Salib, 2013). Hence, for this study, the number of floors will be taken as 60 .

The total set of building morphotypes was programmed using the parametric design interface, Grasshopper, generating solutions from the combination of a reduced set of input parameters. The names and Range of these variables are given in Table 1.

The above-mentioned variables compose the ten variables or chromosomes of the genetic code. Variables 5 and 6 depend on variable 1 and there- 
fore constitute a single variable (chromosome) in the genetic code. The parametric model contains a few other variables for the model generation, but they are not needed for the exploration of genetic variations. One is the floor height which is supposed to be fixed depending on the project type - housing or office building. This value is previously set by the designer. Similarly, the number of floors is fixed. In this case, we assume that the number of floors is not a variable set for optimization assuming that the total number of floors in a specific lot is either given by regulation or by the contractor as design specification. Therefore, the optimization procedure focuses on optimizing the other variables according to a fitness function evaluating the performance in terms of comfortable indoor air velocity, building configuration for affective air flow paths and temperature reduction of indoor air resulting in reduced cooling load as well as the building capacity. A particular instance of the model is given by a specific combination of variables and constitutes the genetic code of that particular instance as the example shown in (Figure 1).

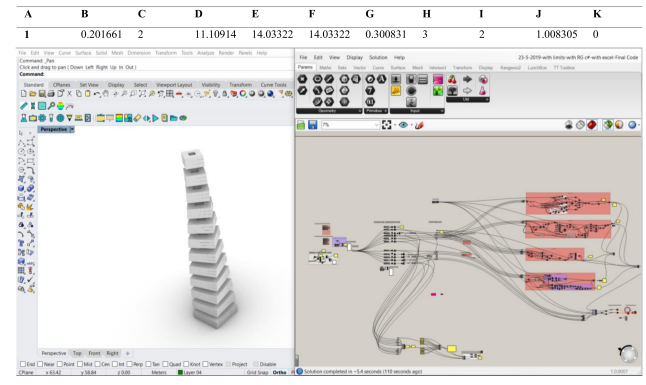

\section{Development of Optimization Model}

Definition of Fitness Function. The fitness value for a tall building is a function of the following factors:

- Temperature reduction of indoor air: According to a study, it has been found that using vegetation on walls and rooftops helps reducing the air temperature in hot climate by min $3-4^{\circ} \mathrm{C}$ locally (Luisa, 2014). Green roofs help reducing surface ambient temperature from 7-10 ${ }^{\circ} \mathrm{C}$, while the outdoor and indoor cooling effect ranges between $0.05-0.6^{\circ} \mathrm{C}$ and 0.4 $1.4{ }^{\circ} \mathrm{C}$, respectively depending on the greenroof type, urban density and time of the day (Morakinyo, Dahanayake, Ng, \& Chow, 2017). However very few studies have been done on the cooling effect of sky-gardens in indoor environment and one of the recent studies indicates that the sky-gardens help reducing indoor air temperature by $0.52^{\circ} \mathrm{C}$ mean to $2.0^{\circ} \mathrm{C}$ max (Mohammadi et al., 2019). This criterion is evaluated using a scale ranging from 0 to 1 representing minimum to maximum values of reduction in air temperature (compared to ambient temperature) inside the ventilation shaft and Sky-Gardens, obtained through CFD simulation using RhinoCFD tool. The higher value on scale, the best is the solution.

- Wind velocity of indoor air: Wind velocity should be in the comfortable range as given by Szokolay $(0.25-1.0 \mathrm{~m} / \mathrm{s})$ in indoors (Szokolay, 2008). However, a wind speed ranging between 8 to $10 \mathrm{~m} / \mathrm{s}$ is considered to be affective for channelizing the optimum flow of air in ventilation shaft and sky garden zones (Stathopoulos \& Dean, 2009). Sky-Gardens can generate high wind velocity up to $10 \mathrm{~m} / \mathrm{s}$ in high-rise buildings; however additions of trees or some other architectural features like space distribution and arrangement of floor plates can reduce it up to $50 \%$ to $80 \%$ (Mohammadi et al., 2019). This criterion is evaluated using a scale ranging from 0 to 1 representing minimum to maximum values of increase in wind velocity (compared to outdoor air velocity) inside the ventilation shaft and Sky-Gardens, obtained through CFD simulation using RhinoCFD tool.

- Building Configuration: It considers the principle that an investor will demand for the best possible ground use considering the le-
Figure 1

Generative Algorithm to develop a 3D-model and its genetic code 
Figure 2

A screenshot of

Grasshopper interface with the algorithm, finding the fitness values of the 3D-models; ranging between 0-10 and representing worst to the best solution
Figure 3

3D-model based on the 3rd Case of 8 samples chosen as random population

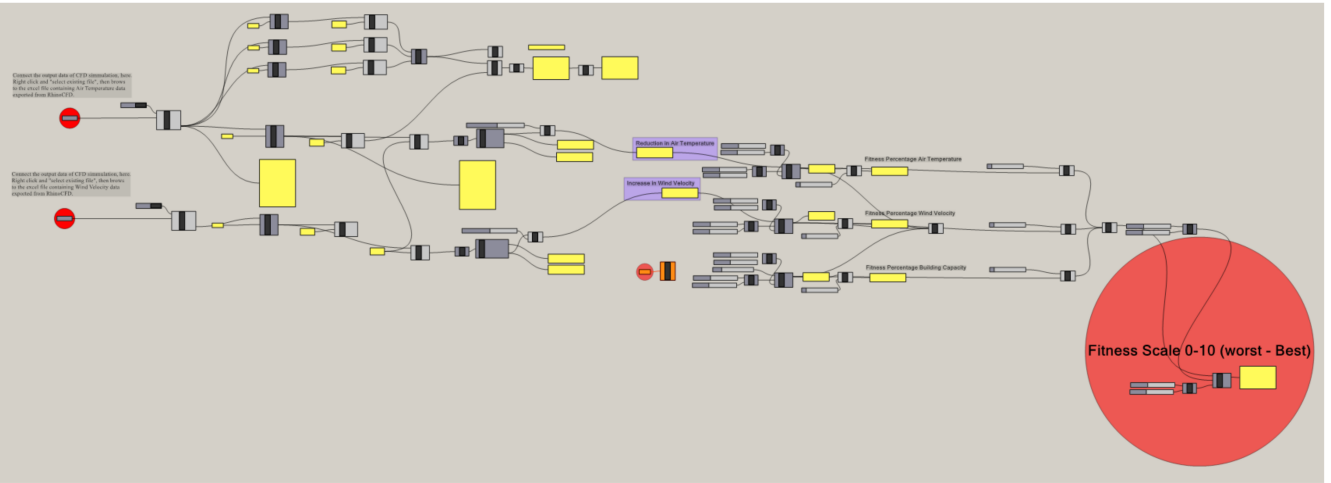

gal constraints of the plot, and therefore that investor will be wanting the maximum possible area while keeping the other evaluation criteria. So, in this case more area means better building configuration. Hence the Gross floor area of the building should be maximum following the floor plan depth ranging between 10 to $21 \mathrm{~m}$ from facade to central ventilation shaft which is generally reported to be most effective depth in terms of natural ventilation process (Aslan \& Sev, 2014; David \& Brian, 2008; Wood \& Salib, 2013).X = f [CFD (Treduced, Vwind ), Plan width]Where $X$ is the fitness value or rank. This function ranks each solution on a scale of 0-10 representing worst to the best options.

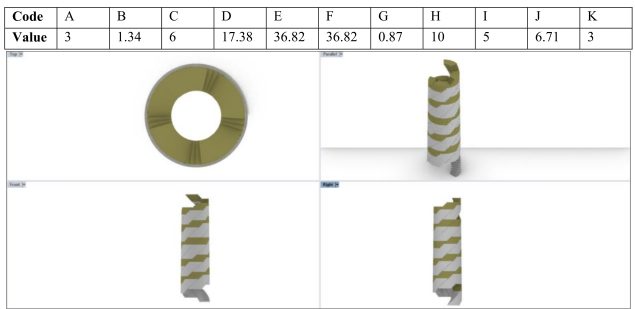

CFD simulation of a random population; Results and Discussions. A CFD simulation of a random pop- ulation was done comprising 8 samples of 3D-Models of tall buildings. The tool used for simulation was RhinoCFD. The results of only one case are presented here due to word and space limitation. The Figure 3 shows different views of Case- 03 with sky-gardens space (in green color) whose CFD results are being presented in Figure 4 and Figure 5

The total computational domain has $60 \times 60 \times 40(\mathrm{~L}$ $\times \mathrm{W} \times \mathrm{H}$ ) cells in FLAIR for a simulation. Domain was characterised by the wind and solar data taken from weather data of Singapore. The data was taken of August 01 and time $1 \mathrm{pm}$ When; wind velocity= $5.1 \mathrm{~m} / \mathrm{s}$, wind direction $=170$ degrees from $y$-axis and ambient temperature $=26^{\circ} \mathrm{C}$. Turbulence Model used is Chenkim KE.In order to evaluate temperature reduction due to foliage (vegetation), energy source is switched to Fixed Heat Flux for foliage for a negative value of $300 \mathrm{~W} / \mathrm{m} 3$ as cooling affect due to vegetation (Timmermans et al., 2014). The Model is analysed as an isolated building with the terrain type as open flat terrain with few grasses and few isolated obstacles. Relaxation factor for convergence control is taken as 0.001 that is global convergence criteria. Total number of iterations are 1000.Figure 4a shows the effect of vegetation on temperature reduction. From the results it was found that the minimum temperature is recorded as $25.3^{\circ} \mathrm{C}$. Also, this lowest temperature of air is attained after it passed through the vegetation. Hence a reduction of $0.1-0.7^{\circ} \mathrm{C}$ in indoor air temper- 


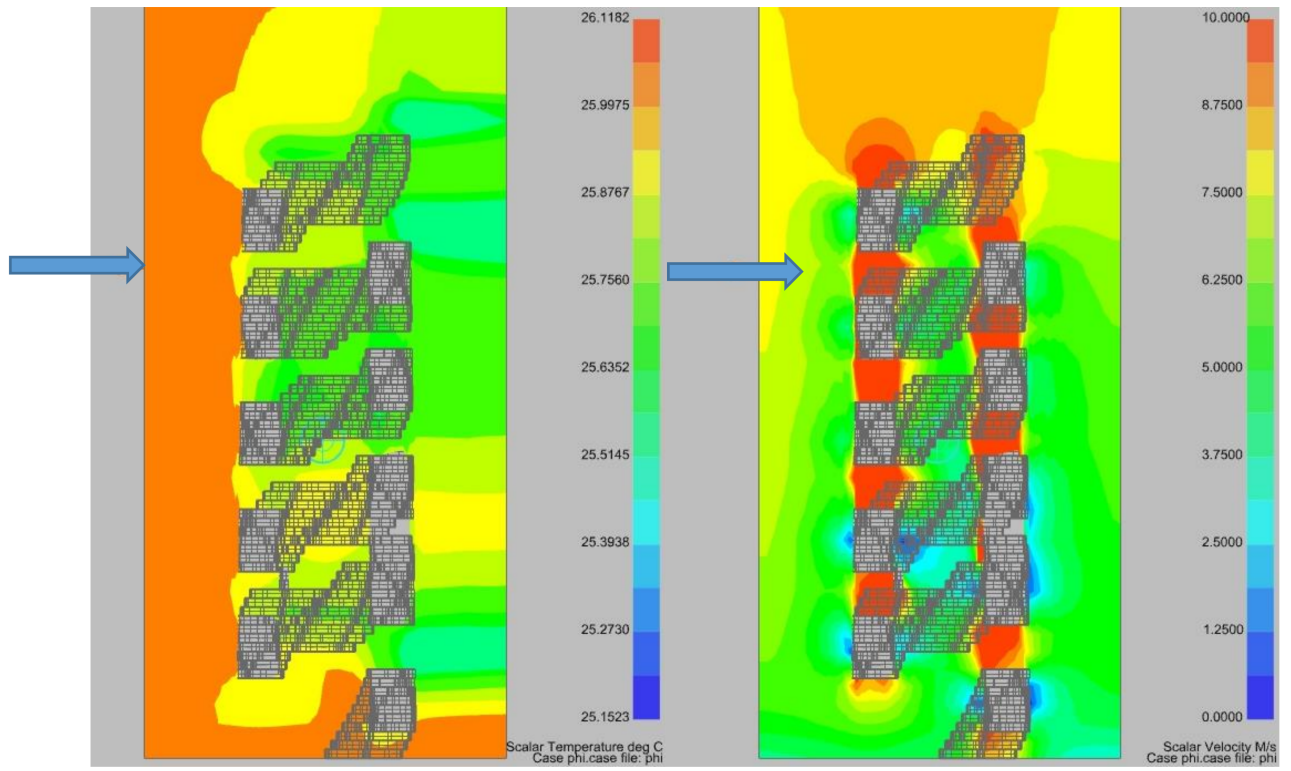

ature has been attained due to vegetation in sky gardens. Blue arrow shows the direction of wind.

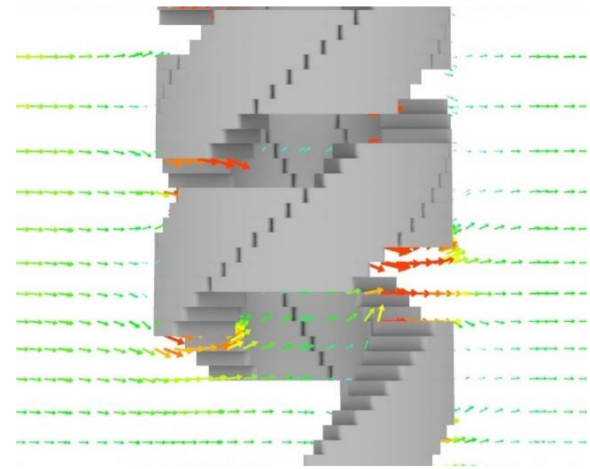

Figure $4 \mathrm{~b}$ show the behaviour of wind velocity while passing through the building. The wind veloc- ity has been increased after passing through vegetation. The wind comes towards windward façade and it slows down near the building surface and changes its direction to the sides of building where it gains more speed. While the vortex is generated on the leeward façade due to negative pressure. The configuration of the building is in a way that inlet and outlet are at different heights, so the stack affect is basically occurring in small steps and enters from one floor and exists from the floors above. This phenomenon can be seen clearly in the Figure 6 .

For this case maximum value of velocity of the wind passing through the Sky Gardens is recorded as $10.7 \mathrm{~m} / \mathrm{s}$. Similar results have been driven by (Mohammadi et al., 2019). A CFD simulation of a sample of 8 Models of tall buildings suggests that after passing through the sky/gardens the wind temperature is reduced between 0.3 to $1{ }^{\circ} \mathrm{C}$ while the wind velocity is increased ranging between 10 to $20 \mathrm{~m} / \mathrm{s}$. This phe-
Figure 4

a)Air temperature on a cut-plane passing through the centre of building and parallel to the wind direction, b) Wind velocity on a cut-plane passing through the centre of building and parallel to the wind direction

Figure 5

Close up of the model near ground floor 
Figure 6

Optimization model applied to a random population

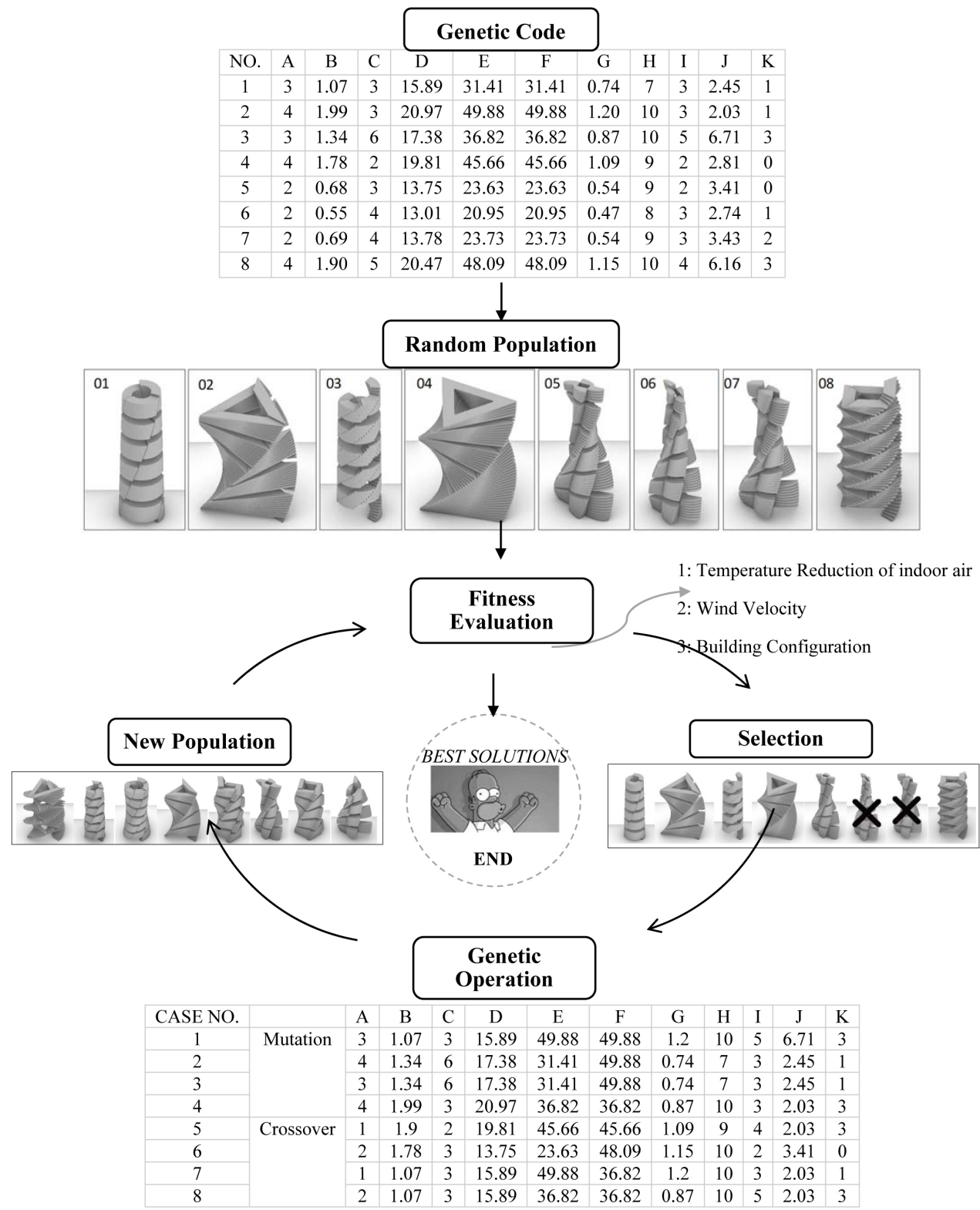

Design - ALGORITHMIC AND PARAMETRIC 2 - Volume 2 - eCAADe 37 / SIGraDi 23 | 651 
nomenon, however, because of building configuration makes the natural ventilation a complex process and it can bring out the best to the worst solutions depending on the genetic code definitions. The fitness function provides a multi-criteria evaluation of these results as previously defined.

Application of Optimization Model. The GA applied to this study is shown in Figure 6. A random function generates a set of genetic codes for generating a population of individuals. The genetic code is composed of the ten above mentioned variables or chromosomes. The range of the variables is pre-set within architecturally meaningful values so that the code may only generate physically coherent buildings. The parametric Grasshopper code generates the population according to the generated genetic codes. Once defined the initial random population, the optimization procedure enters a loop involving a set of steps. In the first step of the loop, the population is subjected to the evaluation procedure using the fitness function where both the CFD analysis and building capacity are evaluated. The fitness function algorithm ranks the population according to the defined criteria above and selects the half best ranked. In the following step, the algorithm applies a genetic operation (e.g. mutation, crossover) to a selection of $75 \%$ of the best ranked selection and generates another random number of individuals which are added to the selected set and submitted to a second round of this loop. The process repeats through various loops until the selected best ranked starts showing irrelevant improvements between loops. At this point the designer is left with a selection of optimized solutions and also provided with the variables' variation range producing the optimized solutions. Such information provides not only a set of available optimal solutions but also the genetic information to produce others. The designer is therefore free to (designerly ) explore this information to further improve the design involving other aspects of the design problem that were not included before. The application of Optimization Model to a random population of 8 samples has been done in the manner shown in Figure 6.

\section{CONCLUSION}

The present paper presents a study aiming at the development of a design interface for the optimization of natural ventilation in the design of tall buildings. The developed system is composed of a building design generator and a genetic optimization system evaluating results according to a fitness function designed to evaluate the building's natural ventilation performance. The design generator generates multiple design solutions following the instructions given in the form of genetic codes. The design solutions are then evaluated with a fitness function that assesses their natural ventilation performance. The optimization system loops the best fit designs together with additional randomly generated solutions until the results of the best fit show little improvement between generations. The paper puts the focus on two aspects of the system: (1) the random design generator and (2) the natural ventilation performance evaluation including the definition of the fitness function. These are the two essential parts of the genetic algorithm, but until this moment these are separate codes running on different software platforms. The genetic loops or generations are presently produced by running the interfaces separately. For the final step of this research a single but complex step is yet to be concluded: linking automatically the loops, i.e., linking generation, evaluation, selection, new generation and so on.

The CFD analysis was able to detect the expected reductions in temperature and the fitness function to rank the set of solutions according to its input variables. The temperature reductions in the simulations present variations between $0.3 \otimes$ and $1 \otimes$ showing that some solutions are able to reduce temperature more than others. Still, depending on the context climate one might argue that this temperature reduction is not enough. In this regard we need discuss a few points:

- Our results are obtained assuming a fixed capacity of sky-gardens of inducing a specific 
cooling effect. The design of the sky-garden is not discussed nor explored in all its variables. It is simply taken as a cooling device with a specific cooling effect. If the design variables of a sky garden are also taken into consideration, it could be possible to induce higher temperature reduction. Such exploration should be done according to specific types of climates to evaluate the types of design producing the most effective cooling behavior. For example, in hot humid climates it could be useful to explore the use of materials that capture moisture and are simultaneously use to pass the air through to induce the cooling effect.

- As the wind speed is reported as always faster at the sky-gardens and the sky-gardens are responsible for temperature reduction, one wonders if designing elements to reduce the wind speed at the sky-gardens would possibly reduce further the temperature in the advantage of the whole ventilation system.

- Different types of vegetation may provide different types of sky-garden response increasing humidity if needed or decreasing humidity if species collecting humidity from the air are use in the sky-garden.

- The construction materials of the sky-gardens may complement the effects of the vegetation especially in relation to the possibility of capturing air humidity (useful in humid climates) and using the water/humidity thus collected to further cool the air.

- Finally, the design of the façade elements and the systems for air admittance inward shall play a fundamental role in making the best use of the detected behaviours provided by the analysis (but this is design detailing and not conceptual design decision).

To conclude we may point that the presented system interface does have the potential to inform designers about the building morphotypes that best respond to the fitness function, but although this may be con- sidered to be a step towards building sustainability, we should also pinpoint the insufficiency of this as the single aspects to manipulate in the design of tall buildings even if looking just at natural ventilation. Future work requires the combination of more factors involved in the design of the building addressing the many aspects referred in this discussion.

\section{REFERENCES}

Bing, W and Ali, M 2015 'Genetic Algorithm Based Building Form Optimization Study for Natural Ventilation Potential', In 14th Conference of International Building Performance Simulation Association, Hyderabad, India.

Emanuele, N, Alessandro, M, Ivan, K and Yi, Z 2013 'A Comparison of conventional, parametric and evolutionary optimization approaches for the architectural design of nearly zero energy buildings', 13th Conference of International Building Performance Simulation Association, Chamb'ery, France

Etheridge, D 2008 'Natural Ventilation of Tall BuildingsOptions and Limitations', CBHU 2008 8th World Congress, Dubai

Fasoulaki, E 2007 'Genetic Algorithms in Architecture: a Necessity or a Trend?', 10th Generative Art International Conference, Milan, Italy

Feng, Y, Shuyi, $\mathrm{H}$ and Tong, $\mathrm{X} 2016$ 'PHYSICAL AND NUMERICAL SIMULATION AS A GENERATIVE DESIGN TOOL Formation of a high-rise typology using wind tunnel testing and CFD simulation', 21st International Conference of the Association for ComputerAided Architectural Design Research in Asia CAADRIA, Hong Kong., pp. 353-362

Gottmann, J 1966, "Why the Skyscraper?', Geographical Review, 56(2), p. 190

Hui, SC 2001, 'Low energy building design in high density urban cities', Renewable Energy, 24(3-4), pp. 627640

Jie, Y, Guangbei, T and Yik, F 2004 'Natural ventilation of highrise residential buildings with sky garden', $H V$ $\& A C$

Kubota, T and Ahmad, S 2006, 'Wind Environment Evaluation of Neighborhood Areas in Major Towns of Malaysia', Journal of Asian Architecture and Building Engineering, 5(1), pp. 199-206

Luisa, P 2014 'Vegetation and Thermal comfort in temperate areas: proposal of an integrated methodology for urban and building retrofit', CONFERENZA ITALIANA DI SCIENZE REGIONALI AISRe. Uscire dalla 
crisi. Citt'a, Comunit'a e Specializzazione Intelligenti, pp. 1-17

Moghaddam, EH, Amindeldar, S and Besharatizadeh, A 2011, 'New Approach to Natural Ventilation in Public Buildings Inspired by Iranian's Traditional Windcatcher', Procedia Engineering, 21, pp. 42-52

Mohammadi, M and Kaiser Calautit, J 2019, 'Numerical Investigation of the Wind and Thermal Conditions in Sky Gardens in High-Rise Buildings', Energies, 12(7), p. 1380

Morakinyo, TE, Dahanayake, KWDKC, Ng, E and Chow, CL 2017, 'Temperature and cooling demand reduction by green-roof types in different climates and urban densities: A co-simulation parametric study', Energy and Buildings, 145 , pp. 226-237

Mughal, H and Corrao, R 2018 'Role of Sky-gardens in Improving Energy Performance of Tall Buildings', International Conference on Seismic and Energy Renovation for Sustainable Cities (SER4SC 2018), Catania Sicily - Italy

Niu, J and Burnett, J 2001, 'Setting up the criteria and credit-awarding scheme for building interior material selection to achieve better indoor air quality', Environment International, 26(7-8), pp. 573-580

Oberndorfer, E, Lundholm, J, Bass, B, Coffman, RR, Doshi, H, Dunnett, N, Gaffin, S, K"ohler, M, Liu, KKY and Rowe, B 2007, 'Green Roofs as Urban Ecosystems: Ecological Structures, Functions, and Services', BioScience, 57(10), pp. 823-833

Oldfield, P, Trabucco, D and Wood, A 2009, 'Five energy generations of tall buildings: an historical analysis of energy consumption in high-rise buildings', The Journal of Architecture, 14(5), pp. 591-613

Raji, B, Tenpierik, MJ and van den Dobbelsteen, A 2016 'Passive performance and building form: An optimization framework for early-stage design support', Solar Energy, 125, pp. 161-179

Raji,, Babak, 2015, 'The impact of greening systems on building energy performance: A literature review', Renewable and Sustainable Energy Reviews, 45, pp. 610-623

Safarik, D, Ursini, S and Wood, A 2018, 'Megacities and tall buildings: symbiosis', E3S Web of Conferences, 33, p. 01001

Serras, JM and Valente, D 2012, Tall Buildings and Elevators Historical Evolution of Vertical Communication Systems, Master's Thesis, Instituto Superior Técnico,IISBOA

Sev, AJ and Aslan, G 2014, 'Natural Ventilation for the Sustainable Tall Office Buildings of the Future', International Journal of Civil, Environmental, Structural,
Construction and Architectural Engineering,, 8(8), pp. 897-909

Stathopoulos, T and Dean, A 2009 'Wind and Comfort', 5th European and African Conference on Wind Engineering, EACWE 5, Proceedings, Florence, Italy

Szokolay, SV 2008, Introduction to architectural science : the basis of sustainable design, Elsevier/Architectural Press

Taib, N, Abdullah, A, Fairuz Syed Fadzil, S and Swee Yeok, F 2010, 'An Assessment of Thermal Comfort and Users', Journal of Sustainable Development, 3(4), pp. 153-164

Timmermans, H, van Hooff, T, Merema, B, Janssen, W, Blocken, B and Gromke, C 2014, 'CFD analysis of transpirational cooling by vegetation: Case study for specific meteorological conditions during a heat wave in Arnhem, Netherlands', Building and Environment, 83, pp. 11-26

Trabucco, D and Wood, A 2016, 'LCA of tall buildings: Still a long way to go', Journal of Building Engineering, 7, pp. 379-381

Wood, A and Salib, R 2012, Natural ventilation in high-rise office buildings, CTBUH in conjunction with IIT and Routledge / Taylor and Francis Group, Chicago, 2012 [1] https://ctbuh.org/uploads/CTBUH囚extbackslash_He ightCriteria.pdf 